\title{
Permian Aquatic Reptiles
}

\author{
Mark A. S. McMenamin ${ }^{1, *}$ \\ ${ }^{1}$ Department of Geology and Geography, Mount Holyoke College, South Hadley, Massachusetts, United States \\ *Correspondence: mmcmenam@mtholyoke.edu; Tel.: 413-538-2280
}

\begin{abstract}
Eight amniote genera (representing four clades) became aquatic during the Permian. The four clades were mesosaurids, tangasaurids, the neodiapsid Claudiosaurus, and the procolophonid Barasaurus. Two of eight genera survived the end-Permian mass extinction, but did not last long into the Mesozoic. A previously undescribed specimen of Claudiosaurus germaini, preserved in a lacustrine concretion from the Sakamena Formation, Madagascar, bears seventeen vertebrae that has been split along an approximate horizontal plane to reveal sections of neural canal casted in white calcite. Enlargement of the neural canal in the sacral region of this specimen of Claudiosaurus (vertebral segments 22-26) is more similar to that of Tupinambis (segments 24-28) than it is to Testudo (segments 16-23). Claudiosaurus skeletal anatomy provides evidence for swim propulsion by both hind limbs and by undulation of a dorsal-ventrally flattened tail. Evidence for the latter includes elongate transverse processes on distal tail vertebrae. Other Permian aquatic reptile genera (Mesosaurus, Hovasaurus, Barasaurus) used snake-like side-to-side tail undulation, whereas Claudiosaurus used cetacean-like up-down tail undulation in the vertical plane. It seems unlikely that any of these animals were particularly fast swimmers.
\end{abstract}

Keywords aquatic reptiles, parareptiles, procolophonids, neodiapsids, Permian, Barasaurus, mesosaurs, Hovasaurus, Tangasauridae, Claudiosaurus, neuroanatomy, swim kinematics, neural canal, caudal vertebrae, transverse process

\section{Introduction}

Mesozoic aquatic reptiles were a diverse group that included ichthyosaurs, plesiosaurs, thallatosaurs, thallatosuchians such as Dakosaurus, nothosaurs, pachypleurosaurs, placodonts, the shovel-jawed marine reptile Atopodentatus, the herbivorous marine sphenodontian Ankylosphenodon, sea turtles, palaeophilid sea snakes, and mosasaurs [1].

Paleozoic aquatic reptiles are much less diverse, but nevertheless interesting as they represent the vanguard of amnintec returnino to the water Althnuoh several oenera
(Barasaurus and Hovasaurus) survived the Permo-Triassic mass extinction, in spite of opportunities to do so none of these Paleozoic aquatic reptile lineages underwent major diversification in marine habitats.

\section{Modifications for Aquatic Life}

A series of repeated and predictable sclerotome modifications occur in amniote tetrapods after they return to an aquatic lifestyle. Before listing these modifications, it is important to note that several aquatic reptiles today (certain crocodilians, marine iguanas [Amblyrhynchus cristatus], nile monitors [Varanus niloticus]) may show few if any discernible modification to their sclerotome resulting from their aquatic lifestyle. That said, skeletal changes in support of an aquatic lifestyle include the following: 1, changes in neck length; 2, decreased ossification of limb joints; 3, thickening of the neural canal associated with enervation demands of swim propulsion; 4, modification of fore and/or hind limbs into flippers, with or without development of hyperphalangy [1]; 5, thickening of the ribs for ballast (pachyostosis, which involves additions of lamellar bone); 6 , changes in the number of caudal vertebrae [2]; 7, enlarged coracoid or bone fusion to form scapulocoracoid; 8 , changes in rib length; 9, enlarged humerus with expanded entepicondyle and corresponding foramina; 10, elongate neural spines on the caudal vertebrae for enhanced tail propulsion; 11, enlarged transverse processes (caudal ribs) in vertebrae at the base of the tail; 12 , transverse processes at the base of the tail curve to the anterior; 13, changes in forelimb length; 14, reduced ossification in the carpals and tarsals, ostensibly to provide greater swimming flexibility. Expansion of the entepicondyle improves the efficiency of the forelimb swimming stroke, but this feature is not exclusive to marine reptiles, as it is also seen in the terrestrial Permian neodiapsid Thadeosaurus. A role likely comparable to that of the expanded entepicondyle was played by the enlarged and flattened ulna in Triassic Keichousaurus. In the category of behavioral modifications for aquatic life, small stones may also be ingested for ballast, as in Hovasaurus.

Scoliosis has been reported from Paleozoic aquatic reptiles [3, 4]. Whether or not these deformities correlate to osteological modifications acquired during transition to an 
that the hydrostatic support provided by an aquatic habitat would somewhat reduce the lethality of sclerotome aberrations as they would not have the same biomechanical requirements as would be the case for land tetrapod skeletons.

\section{Paleozoic Aquatic Reptiles}

Amniotes first appear in the Carboniferous at $312 \mathrm{Ma}$ [5]. There are no reported cases of return to aquatic lifestyle among Carboniferous amniotes. By the Early Permian, however, several lineages had returned to the water. All of these consisted of relatively small animals, most less than a meter in length.

The three Early Permian genera belong to the Mesosauridae (Mesosaurus, Stereosternum and Brazilosaurus). These are followed by Late Permian genera belonging to the aquatic neodiapsid family Tangasauridae (Tangasaurus, Acerosodontosaurus, and Hovasaurus). Thus the Permian sees two radiations of marine reptiles, an earlier one consisting of mesosaurids and a later one consisting of tangasaurids.

Two additional genera added to the Late Permian diversification include the neodiapsid Claudiosaurus and Barasaurus, the only known aquatic procolophonid. As is the case for Hovasaurus, Barasaurus survives for a short time into the Triassic.

\section{Acerosodontosaurus}

Acerosodontosaurus is an aquatic neodiapsid, closely related to Hovasaurus. Acerosodontosaurus is thought to have reached a total length of $70 \mathrm{~cm}$. Its skull has lost the quadratojugal and thus develops a spacious lower temporal arcade [6]. Acerosodontosaurus's humeri have enlarged entepicondyles with corresponding foramina. Acerosodontosaurus' femur is thicker than that of the related terrestrial neodiapsid Kenyasaurus.

\section{Barasaurus}

The typical procolophonoid parareptile (such as Hypsognathus) is a rather squat creature with a pair of pointed projections that jut out from the back of its skull, giving the animal a resemblance to a desert horned lizard. Interestingly, there was one successful aquatic procolophonoid, Barasaurus. The existence of Barasaurus recalls the single known successful aquatic sphenodontian, Ankylosphenodon from the Early Cretaceous of México [7].

Barasaurus, as is true of all procolophonoids, is characterized by its fused astragalocancaneum (Figs. 1-3; [3]). Its squamation consisting of large (up to $4 \mathrm{~mm}$ greatest dimension on an animal approximately $30 \mathrm{~cm}$ in length), skink-like ventral scales in a configuration that was well suited for existence in an aquatic habitat. The Barasaurus lifestyle was comparable to that of the crab-eating modern
Cuban aquatic anole (Anolis vermiculatus [8]). Although Barasaurus had the potential to do, especially considering that it survived the Permo-Triassic mass extinction, the genus did not diversify into a major group of Mesozoic marine tetrapods.

\section{Brazilosaurus}

Mesosaurids of Mesosauridae, constituting a part of the Sauropsida, form a sister group to all other reptiles (Parareptilia and Eureptilia, respectively). This puts mesosaurids in a curious phylogenetic position between synapsids and Reptilia. Indeed, suggestions that mesosaurids may be synapsids themselves have recently resurfaced [9]. It remains unclear at this point whether mesosaurids are basal Parareptilia, Synapsida, or basal Sauropsida, an unsettled placement for this iconic group of Permian aquatic creatures, famous for their role in establishing the Pangaean paleobiogeographic linkage between South America and Africa.

Brazilosaurus is one of the three described mesosaurid genera, and along with Mesosaurus occurs in Brazil [10]. Brazilosaurus has considerably smaller teeth than either Stereosternum or Mesosaurus [11].

\section{Claudiosaurus}

Known from the Sakamena Formation of Madagascar, Claudiosaurus is the most basal neodiapsid and thus occupies an important position in diapsid phylogeny, close to the Carboniferous-Permian Order Araeoscelidia. The largest claudiosaur individuals reach up to $60 \mathrm{~cm}$ length. The fibula has a gentle S-shaped curve, comparable that of its terrestrial presumed close relative Thadeosaurus.

In Claudiosaurus, the transverse vertebral processes occurring at the tail base are large and elongate, and curved in an anterior direction, evidently as muscle attachments for the powerful caudofemoralis musculature that powered the hind limbs. The width of the long, narrow trunk vertebrae in Claudiosaurus are roughly $50 \%$ of their length, as opposed to Thadeosaurus where the ratio is $70 \%$ [12].

In Claudiosaurus, the "centra of the two principal sacrals and the first four caudals are as long as the longest trunk centra, after which the length somewhat decreases" [12]. Also, in addition to two pairs of primary sacral ribs, a third pair is partially incorporated into the sacrum [12]. Growth rings occur on the zygapophyses of the trunk vertebrae [12].

The margins of contact in the carpals "are poorly defined" and therefore retained considerable cartilage, providing a greater 'degree of flexibility' that would be beneficial for swimming [12]. In Thadeosaurus, by comparison, the carpals are much more thoroughly ossified [12]. Whether or not Claudiosaurus had webbed feet (a popular trope in paleoartistic renderings of the creature) is at present conjectural.

Claudiosaurus was at one time considered ancestral to 
Sauropterygia are now included in Pantestudines. Pantestudines includes animals that are less closely related to other tetrapods than they are to turtles [13]. The true ancestor to plesiosaurs probably resembled the basal sauropterygian Keichousaurus (Triassic).

There is a certain irony in sauropterygians now being considered "stem-turtles" of Pantestudines, as Plesiosaurus was famously described by William Buckland in the 1820 s as "a snake threaded through the shell of a turtle." Although not closely related to sauropterygians, Claudiosaurus nevertheless does bear a general if superficial resemblance to sauropterygians.

\section{Hovasaurus}

Hovasaurus is a tangasaurid [14], a member of an important, aquatic early neodiapsid clade that includes Tangasaurus and Acerosodontosaurus. Tangasaurid genera form part of the unranked (and likely polyphyletic [6]) Younginiformes clade that replaces the obsolete taxon Eosuchia. Hovasaurus was the largest tangasaur, but only reached a length of $30 \mathrm{~cm}$. Hovasaurus would ingest small stones for ballast (Fig. 4).

Hovasaurus survived the Permo-Triassic mass extinction event, only to go extinct shortly after the beginning of the Mesozoic.

\section{Mesosaurus}

Mesosaurus (Fig. 5) is the eponymous genus for the three described mesosaurid genera. The genus is well known for its spiky array of large teeth. Mesosaurus tenuidens has the largest teeth known in mesosaurids [11]. Reaching one meter in length, Mesosaurus was the largest Permian aquatic reptile.

Pachyostotic ribs provided ballast (Fig. 6). The primary prey item for Mesosaurus is thought to have been pygocephalomorph crustaceans [15]. Left-right flattening of the tail in Mesosaurus suggests swim propulsion by side-to-side undulation of the tail [15].

\section{Stereosternum}

Stereosternum (Fig. 7) is one of the three described mesosaurid genera. The animal attained $80 \mathrm{~cm}$ length. Teeth in Stereosternum are intermediate in size between the large teeth of Mesosaurus tenuidens and the smaller teeth of Brazilosaurus. The differences in dentition are attributed to differences in diet [11].

Stereosternum has elongate processes on the base-of-tail vertebrae (Fig. 7), however, they curve to the posterior, not the anterior, so the convergence in this regard with Claudiosaurus is imperfect. Note, however, that regarding the base-of-tail transverse processes, with Stereosternum the first three increase in length in a posterior direction. This may have had an effect (in terms of muscle insertion) similar

\section{Claudiosaurus.}

\section{Tangasaurus}

This eponymous member of the Tangasauridae is named for Tanga, Tanzania. The largest specimens of Tangasaurus are $24 \mathrm{~cm}$ in length, and have a laterally-compressed tail that undulated to generate swim propulsion [16]. Tangasaurus is distinguished by elongation of the neural spines of the mid-tail vertebrae, plus elongation of the mid-back (dorsal) neural spines [17], a morphology somewhat reminiscent of the modern green basilisk lizard (Basiliscus plumifrons).

\section{Claudiosaurus Neuroanatomy}

Unlike most modern amniotes, the vertebral column in Claudiosaurus consists of vertebrae with both a notochordal opening (ventral) and a neural canal that held the dorsal spinal column. The sixteenth trunk vertebra in Claudiosaurus has a crested or keeled neural canal opening at its anterior end, and a circular neural canal opening at its posterior end [12]. The anterior opening is similar to the roughly triangular neural canal opening of other reptiles, such as Sphenodon and the madtsoiid snake Madtsoia [18]. The cross sectional shape of the neural canal at the midpoint of the vertebra in Claudiosaurus is reported here for the first time.

Carroll noted that Claudiosaurus ribs are hollow and are now filled with 'crystalline calcite' [12]. In an Claudiosaurus skeleton (sample 1 of 7/3/2019) reported here from a $25 \mathrm{~cm}$ concretion (2099 g.; Sakamena Formation, Madagascar), in a case of exceptional preservation, this same crystalline calcite has casted the dorsal nerve chord. This specimen shows the trunk anatomy, part of the tail and parts of four limbs, with the right forearm virtually intact (Figs. 8-20). The animal is preserved in dorsal view, with breakage revealing gastralia (as seen from their dorsal side) at the midpoint of the body. The specimen is unusual because, when the concretion was split to reveal the fossil, the irregular plane of fracture cleaved approximately 15 or so vertebrae roughly in half, exposing the interior of these vertebrae. The neural canals have been naturally casted by white calcite that precipitated in the space left by decomposition of the spinal cord.

A remarkable result of the fracture plane splitting many of the vertebrae was exposure of this fossil neural canal cast (Figs. 12-18). The calcite infill prevented collapse and distortion of the neural canals during diagenesis, and the calcite cast allows analysis of Claudiosaurus neuroanatomy that might be difficult to study even with micro CT analysis of a specimen with intact vertebrae, particularly if there are density contrast or bone deformation issues.

Neural canal cross-sectional shape does vary along the length of the vertebral column in modern reptiles such as the lizard Tupinambis, thus the assumption employed here that 
used as a proxy for the shape and diameter of the respective neural canal segment seems plausible.

Comparable split vertebrae occur in Claudiosaurus germaini specimen 20/6 [12] but occur in the caudal vertebrae only, and the silicon cast of the specimen as illustrated is not particularly informative in this region. Part of the neural canal is dorsally exposed in caudal vertebrae beyond number 41 [12].

Neural canal anatomy in visible on vertebrae $7,8,12,13$, $14,21,22,23$, sacral 1, sacral 2, caudal vertebrae 1, 2, 3, 4, 5, 6 and isolated $933 / 34$. There is marked expansion in the width of the calcite cast between some of the pairs of vertebrae. Where it can be measured, the diameter of the neural canal is shown in Table 1 . The width of the neural canal as preserved on this specimen varies from $0.7 \mathrm{~mm}$ to almost $4 \mathrm{~mm}$. Trunk vertebra 22 preserves a rapid expansion of the diameter of the neural canal from $2.1 \mathrm{~mm}$ at the anterior end of the vertebra to $3.9 \mathrm{~mm}$ at the posterior end of the centra, adjacent to sacral vertebra 1 .

The comparable sacral expansion of the neural canal in the gold tegu (Tupinambis teguixin) occurs at spinal segment 24. Claudiosaurus has expansion of diameter of the sacral neural canal from segments 22 to 26 (=caudal 1), whereas the swelling occurs in segments 24 to 28 in Tupinambis. By comparison, the Hermann's tortoise (Testudo hermanni) has sacral region neural canal swelling in segments 16-23. The neuroanatomy of Claudiosaurus is considerably more similar to the modern lizard Tupinambis than it is to Testudo.

Table 1: Claudiosaurus germaini neuroanatomical data

\begin{tabular}{|c|c|c|}
\hline vertebra & $\begin{array}{l}\text { approximate neural } \\
\text { canal diameter }(\mathrm{mm})\end{array}$ & $\begin{array}{l}\text { neural canal cross } \\
\text { sectional shape at the } \\
\text { midpoint of the } \\
\text { vertebra }\end{array}$ \\
\hline 7 & 3 & lemon \\
\hline 8 & 3 & lemon \\
\hline 12 & 1.7 & lemon \\
\hline 13 & 2.3 & $?$ \\
\hline 14 & 2.5 & lemon/keel \\
\hline 21 & 2.9 & lemon (?) \\
\hline 22 & $\begin{array}{c}2.1-3.9 \\
\text { expands to posterior }\end{array}$ & lemon/keel \\
\hline 23 & 3.5 & $?$ \\
\hline sacral 1 & 3.3 & rectangular (?) \\
\hline sacral 2 & $\sim 3.2$ & rectangular/pentagonal \\
\hline caudal 1 & $\begin{array}{c}3.8-2.3 \\
\text { contracts distally }\end{array}$ & rectangular \\
\hline caudal 2 & 2 & rectangular \\
\hline caudal 3 & 1.5 & pea sprout \\
\hline caudal 4 & $\begin{array}{c}\sim 1-2+ \\
\text { swells distally }\end{array}$ & pea sprout \\
\hline caudal 5 & $\begin{array}{c}1-3 \\
\text { swells to ends of } \\
\text { vertebra } \\
\end{array}$ & pea sprout \\
\hline caudal 6 & $\begin{array}{c}0.8-2 \\
\text { swells to ends of } \\
\text { vertebra }\end{array}$ & pea sprout \\
\hline audal $? 33 / 34$ & 0.7 & oval \\
\hline
\end{tabular}

Fig. 18 shows the four types of cross sectional shapes for the Claudiosaurus neural canal: lemon, rectangular, pea sprout, and oval. As seen in Table 1, the largest diameter neural canals, in the sacral region, are associated with a rectangular or even rectangular/pentagonal as in sacral vertebra 2.

A distinctive neuroanatomical modification, namely "massive enlargements of spinal segments supplying the hind limbs," has been used to suggest that the extinct pinniped Allodesmus used primarily its hind limbs for swim propulsion [19]. The enlargement of the neural canal in the sacral region of Claudiosaurus, as shown in Table 1, plus its cross-sectional shape change to rectangular/pentagonal, is in accord with the inferences made for Allodesmus [19], and indicates that Claudiosaurus did indeed rely on its hind limbs for swim propulsion. Claudiosaurus represents an early case of neuroanatomical modifications to the tetrapod body plan presumably associated with locomotion. Comparable modifications culminated in the development of the glycogen body (associated with flight) in the synsacrum of birds and dinosaurs [20,21].

\section{Claudiosaurus Swim Kinematics}

In Claudiosaurus, the transverse vertebral processes occurring at the tail base are large and elongate, and are oddly curved in an anterior direction. A similar morphology is seen in Tangasaurus, and also in the small Triassic pachypleurosaur Keichousaurus. This feature has been interpreted as an attachment mechanism for the caudofemoralis musculature (musculus caudofemoralis longus) responsible for the power stroke in hind limbs [16]. The base-of-tail transverse processes would enhance hind limb propulsion efficiency in Claudiosaurus.

Figs. 19-20 show an isolated bone behind the right leg of Claudiosaurus that is inferred here to: 1 , belong to the animal preserved in the concretion, and; 2, to represent caudal vertebra ?33/34 (see also Table 1). In support of inference 1 , the bone is preserved in the same way, with the same permineralized bone color (waxy black) and with the same blocky calcite filling the lacunae and casting the neural canal. In support of inference 2, the preserved bone has the shape of caudal vertebrae 33-34 [12], and is positioned only $13 \mathrm{~mm}$ away from the articulated remains of the tail of the animal. In any case, the bone is apparently reptilian bone as opposed to fish material.

Distal caudal bones preserved as isolated bits in Sakamena Formation concretions are also known in Barasaurus besairiei [3]. In the case of Barasaurus, the caudal vertebrae with their diagnostic hemal arches were preserved when a section of the distal tail curved into the preservation zone of the concretion that had formed concentrically around the pelvic region of the Barasaurus.

The vertebra shown in Fig. 19 bears a right transverse process, preserved as an external cast with no bone remaining. The cast is fairly high relief, bulging toward the viewer near the waist of the centrum. This vertebra 
preserved here); this has been restored in Fig. 20. Unlike the transverse processes of the anterior most caudal vertebrae, the transverse processes of the distal caudal vertebra curve in a posterior direction.

Carroll [12] shows no such elongate, pointed transverse processes in the 30s series caudal vertebrae of Claudiosaurus This must be due to one of the following scenarios. First, the distal transverse processes may have been present in Carroll's [12] specimens of Claudiosaurus germaini, but not preserved. Indeed, only one of the processes is preserved in the specimen shown in Figs. 19-20. Second, the Claudiosaurus specimen described here may represent an undescribed species of Claudiosaurus with elongate distal caudal vertebral transverse processes as a species characteristic. Third, the vertebra in question may not belong to the articulated specimen in the same concretion, or alternatively may not even belong to a Claudiosaurus. I consider the first scenario to be the most likely, namely, that caudal vertebra ?33/34 does indeed belong to this Claudiosaurus individual, and that it shows a rarely preserved feature, a distal transverse process.

Assuming that scenario one is correct, this has important implications for swim dynamics in Claudiosaurus. Elongate distal transverse processes in caudal vertebrae imply a dorsal-ventral flattening of the tail, and thus not a side-to-side tail motion for propulsion as inferred for Hovasaurus with its greatly elongated caudal neural and hemal spines [14], and likewise for Mesosaurus [15], but rather an undulation in the vertical plane as in cetaceans.

Nobu Tamura has depicted just such a swimming pattern in a rendering of Claudiosaurus germaini (Fig. 21), albeit without portraying dorsal-ventral flattening of the tail. Future paleoart renderings claudiosaurids should portray this flattening. Claudiosaurus germaini skeletal anatomy provides evidence for both hind limb propulsion and propulsion by vertical plane undulation of a dorsal-ventrally flattened tail.

\section{Depositional Environment}

Carroll [12] argued for a rift-valley-hosted open marine environment of the Sakamena Formation, in accord with his hypothesis that Claudiosaurus was ancestral to Jurassic plesiosaurs. The depositional environments of the reptile-bearing lower Sakamena beds are in fact lacustrine deposits interbedded with nearshore and fluvial deposits [22]. As the strata were indeed deposited in rift valleys, cause of death of the aquatic reptiles may very well have been thermal shock due to overturn of a lacustrine thermocline [23].

\section{Conclusions}

Four reptilian groups become aquatic during the Permian, first the mesosaurids, followed by the tangasaurids, the early neodiansid Claudiosaurus. and the nrocolonhonid
Barasaurus. It is surprising that none of these animals attained more than one meter in length, for as shown by cetaceans, marine habitats can be supportive of aquatic tetrapod size increase.

A previously undescribed specimen of Claudiosaurus, preserved in a concretion from the Sakamena Formation, Madagascar, shows seventeen vertebrae split along an approximate horizontal plane to reveal a neural canal casted in white calcite. Expansion of the neural canal in the sacral region Claudiosaurus (vertebral segments 22-26) is more similar to that of the lizard Tupinambis teguixin (segments 24-28) than it is to Testudo hermanni (segments 16-23), and distinctly dissimilar to that of the reticulated python (Malayopython reticulatus), an animal which shows no such sacral neural canal enlargement [24, 25]. The differences between Claudiosaurus and Tupinambis are likely controlled by upregulation in Claudiosaurus of Ptch1 (patched 1) and Hhipl (hedgehog-interacting protein 1), both of which serve as hedgehog antagonists [26]. The odd variation of vertebral segmental length in Testudo is more likely due to heterotopic distortion of a more conventional tetrapod body plan [27, 28].

The long transverse processes or caudal vertebrae ribs seen in mesosaurs and Claudiosaurus are likely the product of hypertrophy in the lateral region of the ventromedial half of the dorsolateral half of the somite that gives rise to the axial sclerotome $[29,30]$.

Two different methods of tail swim propulsion were adapted by Permian aquatic reptiles. Several genera (Mesosaurus, Hovasaurus, Barasaurus) used snake-like side-to-side tail undulation, whereas Claudiosaurus used up and down tail undulation. It seems unlikely that any of these animals were particularly fast swimmers [15].

\section{Appendix I: Abbreviations}

ac astragalocalcaneum
cdv caudal vertebra
cf coracoid foramen
cr caudal rib = transverse process
dt distal tarsal
fb fibula
fe femur
g gastralia
h humerus
i intermedium
il ilium
ish ischium
mt metatarsal
mtc metacarpal
p phalanx
pb pubis
r rib ..


sc scapulocoracoid

sr sacral rib

sv sacral vertebra

t tibia

u ulna

\section{Acknowledgements}

Thanks to Max Hawthorne, Mathieu M. Lafreniere, Dianna L. Schulte McMenamin and Jon Tennant for assistance with this research.

\section{Figures}

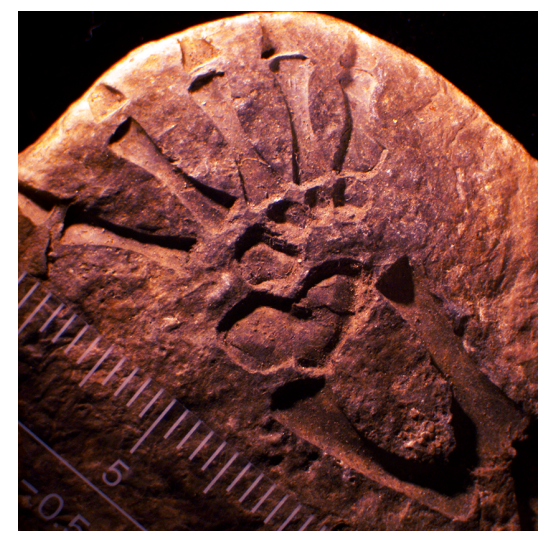

Figure 1. Barasaurus besairiei, right hind limb, dorsal view [3]. The bilobed astragalocalcaneum, visible just below the center of the photograph, is diagnostic for procolophonids. Sample 3 of 10/23/2017; Sakamena

Formation, Madagascar. Scale in millimeters. Image credit: Mark McMenamin.

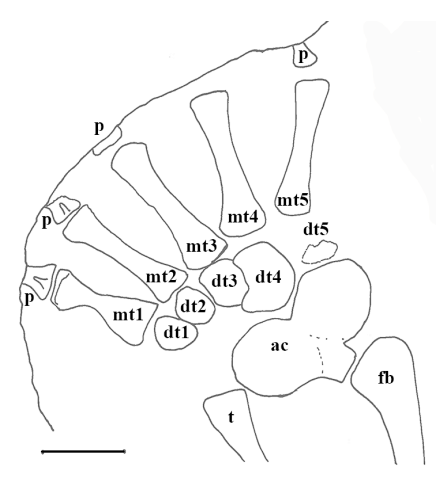

Figure 2. Barasaurus besairiei, right hind limb, ventral view [3]. Note fused astragalocalcaneum (ac). Sample 4 of 10/23/2017; Sakamena Formation, Madagascar. Scale bar $5 \mathrm{~mm}$. Image credit: Mark McMenamin.

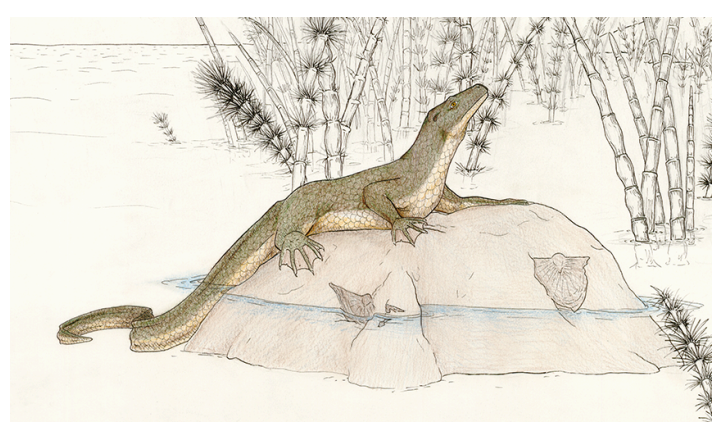

Figure 3. Barasaurus besairiei resting on a fossiliferous shoreline rock. Length of animal $30 \mathrm{~cm}$. Webbed feet are conjectural. PaleoArt credit: Kallie Ellen Fellows. Used with permission.

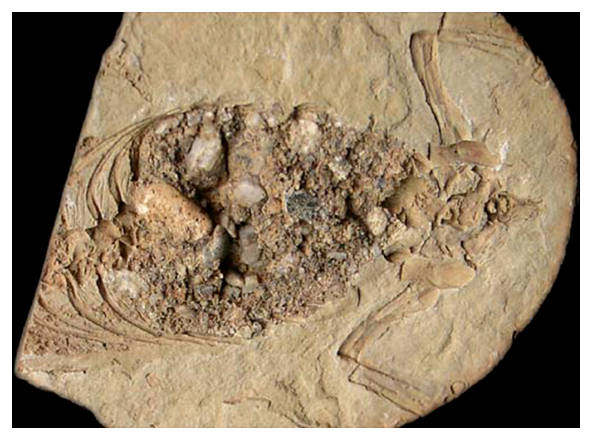

Figure 4. Mesosaurus tenuidens from the Paraná Basin, Brazil (270 Ma) showing pebbles ingested for ballast. Image credit: Oliver Wings. Used here per CC BY 2.0.

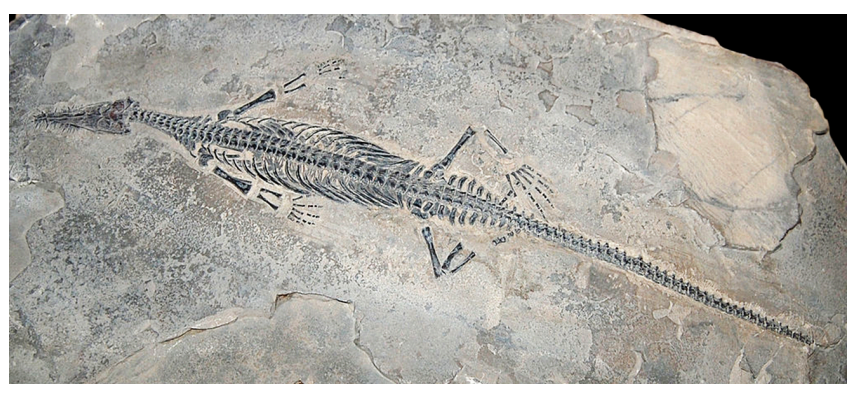

Figure 5. Mesosaurus tenuidens from the Paraná Basin, Brazil (270 Ma). Image credit: Tommy. Used here per CC BY 2.0.

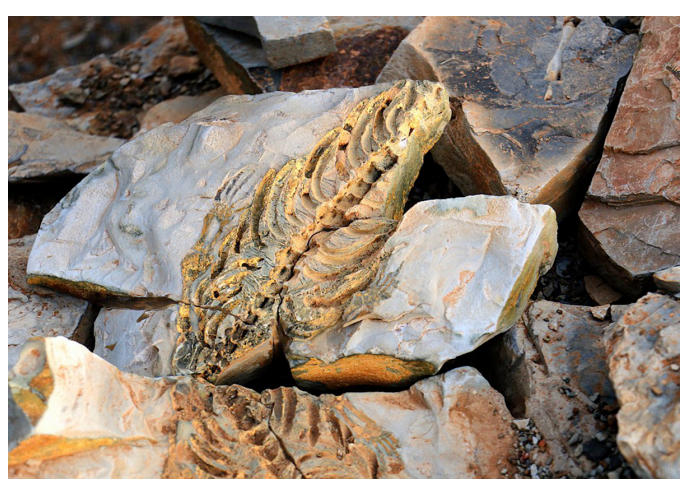

Figure 6. Mesosauridae, likely Mesosaurus sp. from the Whitehill Formation, Aranos Basin, near Keetmanshoop, southeastern Namibia. Note the pachyostotic ribs, thickened for ballast. Image credit: O. Ernst and $\mathrm{H}$. Baumeler. Used here per CC BY-SA 4.0. 


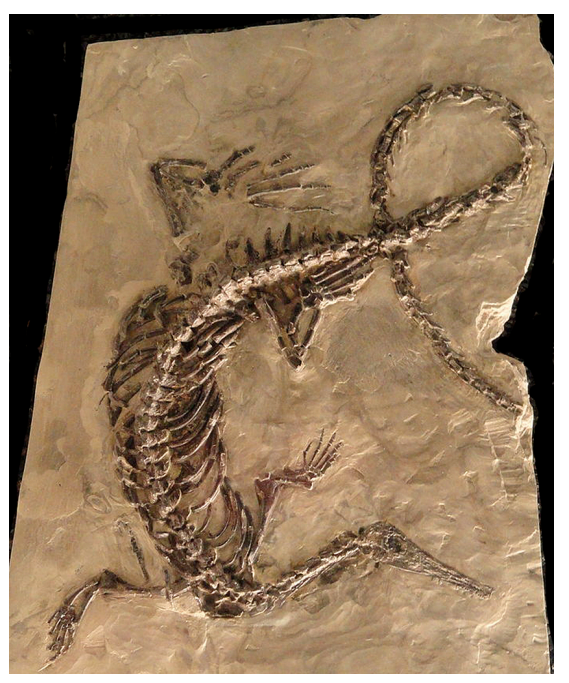

Figure 7. Stereosternum tumidum from Irati, Paraná Basin, Brazil. Note length of base-of-tail transverse processes, and how the first three increase in length in a posterior direction. Image credit: Daderot. Used here per CC0-1.0.

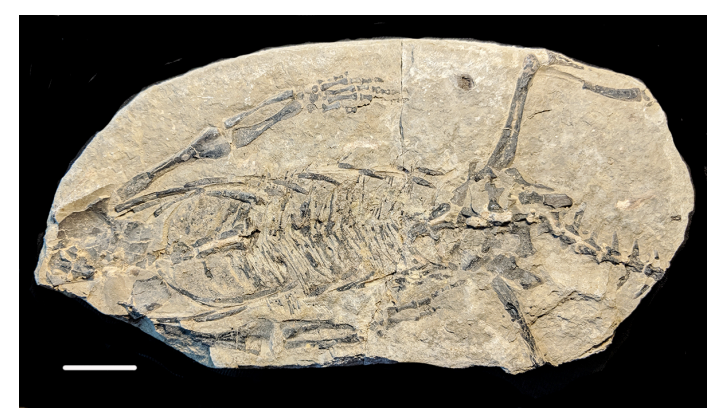

Figure 8. Claudiosaurus germaini. Dorsal view of animal preserved in split calcareous concretion. Sakamena Formation, Madagascar. Sample 1 of 7/3/2019. Scale bar $3 \mathrm{~cm}$. Photo credit: Anthony Tsamoboukos. Used with permission.

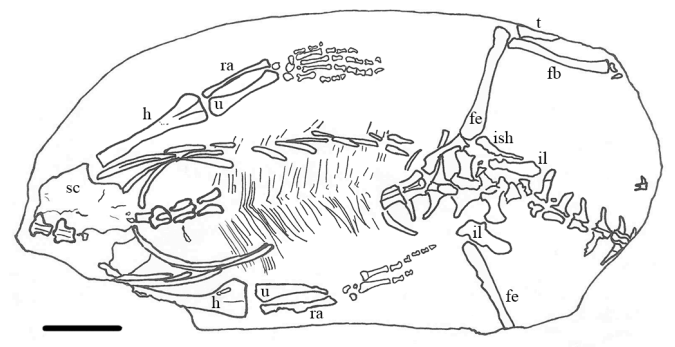

Figure 9. Claudiosaurus germaini. Line art sketch of previous image. Scale bar $3 \mathrm{~cm}$. Image credit: Mark McMenamin.

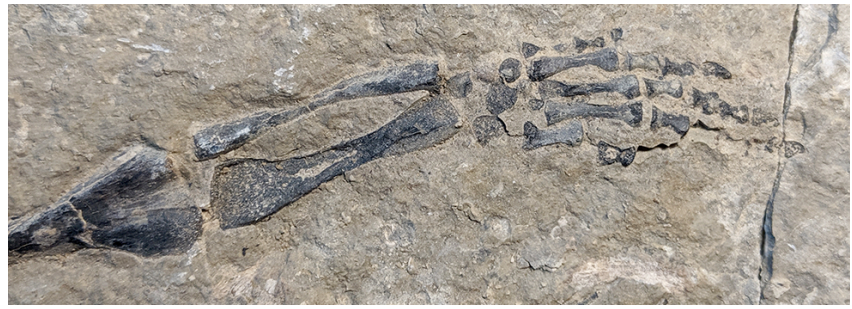

Figure 10. Claudiosaurus germaini. Dorsal view of right arm. Photo credit: Amy McMenamin. Used with permission.

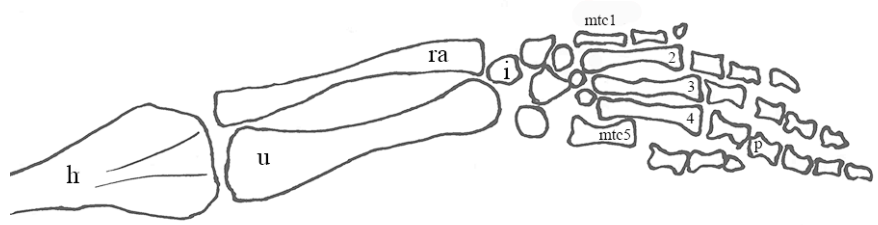

Figure 11. Claudiosaurus germaini. Line art sketch of previous image. Image credit: Mark McMenamin.

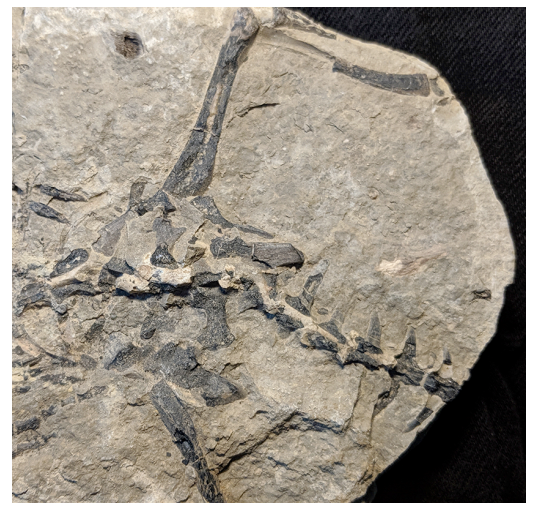

Figure 12. Claudiosaurus germaini. Sacral region showing dorsal view of neural canal cast in white calcite. Presumed caudal vertebra ?33/34 is seen at the right edge of the specimen above the tail. Photo credit: Amy McMenamin. Used with permission.

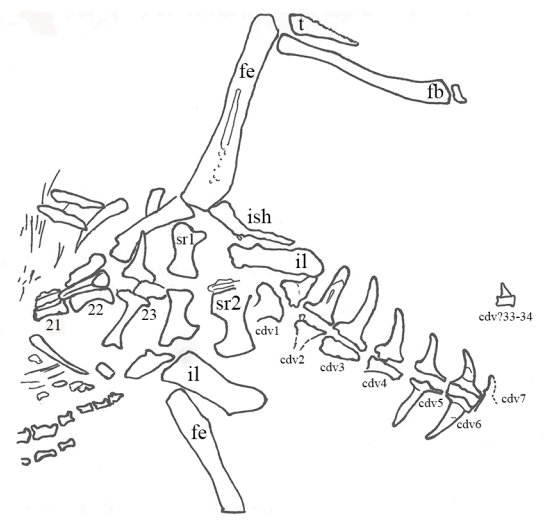

Figure 13. Claudiosaurus germaini. Line art sketch of previous image. Asterisk indicates Elongate femoral ridge or trochanter on the left femur. Image credit: Mark McMenamin. 


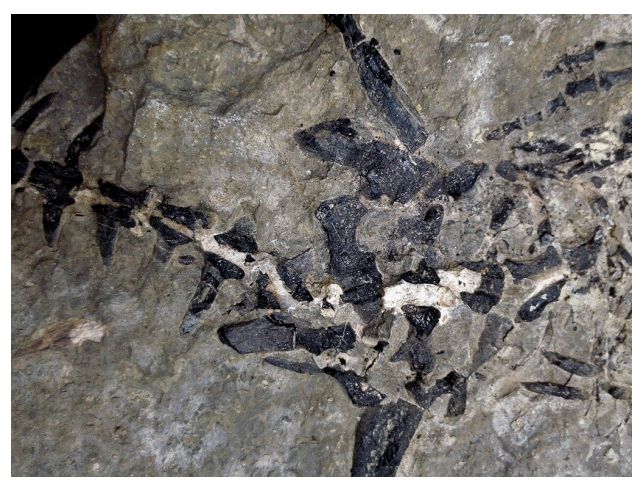

Figure 14. Claudiosaurus germaini. Additional image of sacral region showing dorsal view of neural canal cast in white calcite. Photo credit: Mark McMenamin.

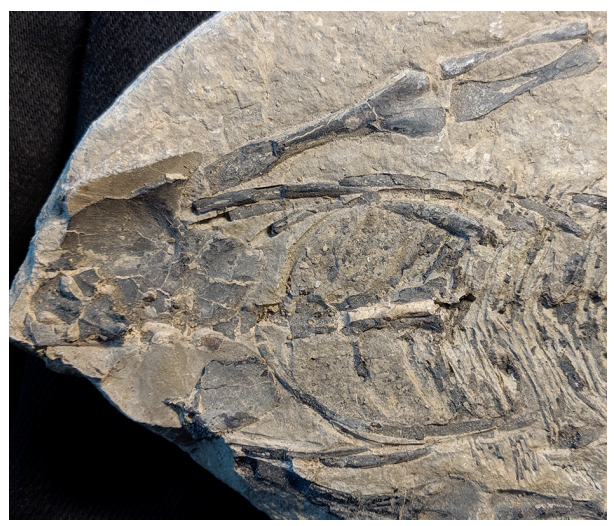

Figure 15. Claudiosaurus germaini. Pectoral region, dorsal view showing neural canal cast in white calcite. Image credit: Amy McMenamin. Used with permission.

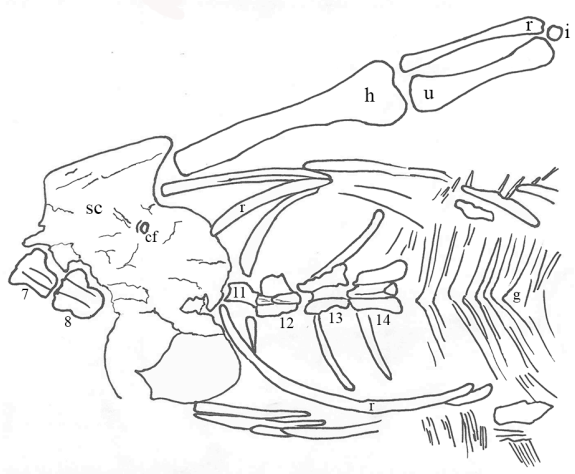

Figure 16. Claudiosaurus germaini. Line art sketch of previous image. Image credit: Mark McMenamin.

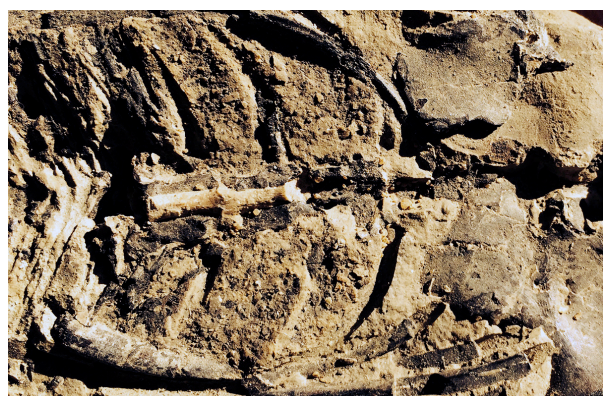

Figure 17. Claudiosaurus germaini. Pectoral region, dorsal view showing neural canal cast in white calcite. Image credit: Mark McMenamin.

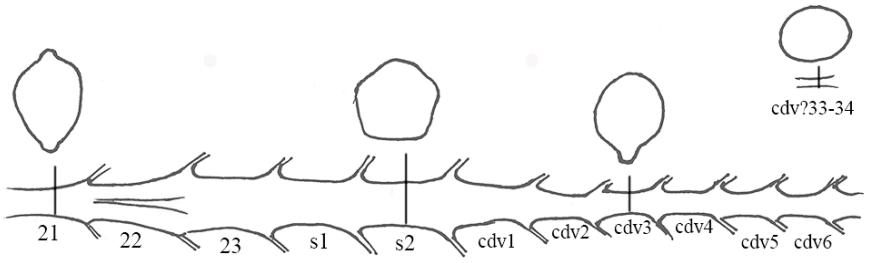

Figure 18. Diagram of part of the Claudiosaurus germaini spinal cord, showing position of spinal nerves of the lumbar, sacral and proximal caudal region. Four types of cross sectional shapes (from left to right: lemon, rectangular, pea sprout, oval) of neural canal along vertebral segments 21-31, plus one presumed distal caudal vertebra. Neural canal outline shown in dorsal view. Vertical lines show line of section through the neural canal. Image credit: Mark McMenamin.

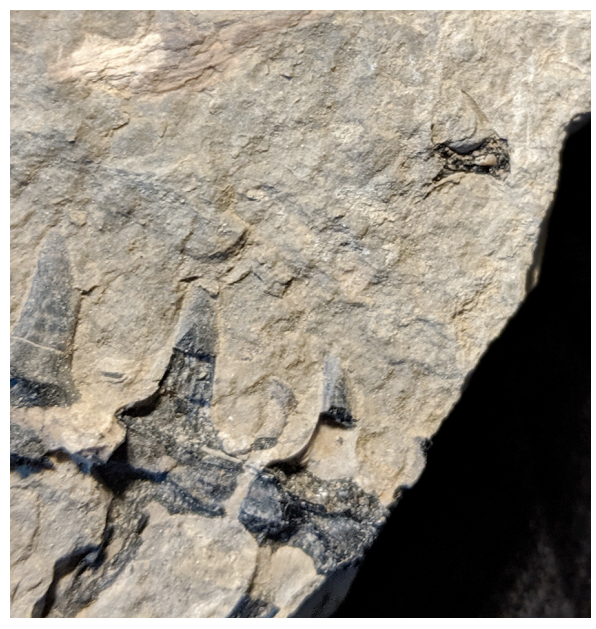

Figure 19. Claudiosaurus germaini. Isolated bone (upper right in image), presumed caudal vertebra $933 / 34$. Ventral view of small vertebra, its anterior to the right. Note preserved right transverse process. Length of vertebra $4.5 \mathrm{~mm}$. Photo credit: Amy McMenamin.

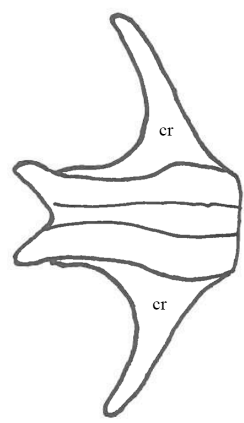

Figure 20. Claudiosaurus germaini. Restored presumed caudal vertebra $? 33 / 34$, ventral view, anterior to the right. Length of vertebra 4.5 $\mathrm{mm}$. Image credit: Mark McMenamin. 


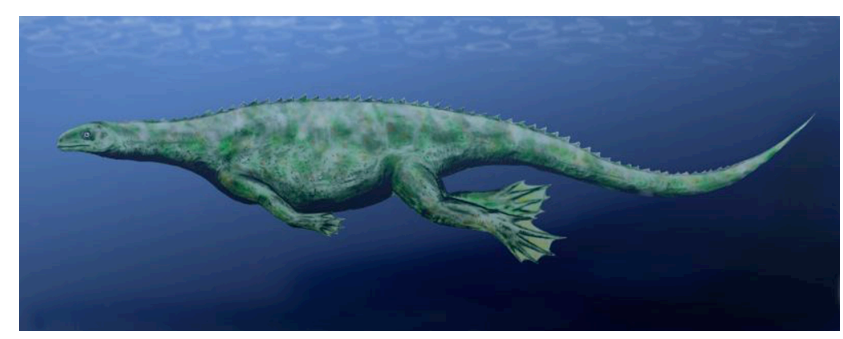

Figure 21. Claudiosaurus germaini. Reconstruction of swimming animal. Webbed appendages are conjectural. PaleoArt credit: Nobu Tamura. Used here per CC BY 2.5 .

\section{REFERENCES}

[1] Sgarbi, G.N.C.; Bittencourt, J.; Harinho, T.S. Répteis que um doa dominaram os mares. Terrae Didatica 2016, 12, 69-77.

[2] Osborn, H.F. The Reptilian Subclasses Diapsida and Synapsida and the Early History of the Diaptosauria, Volume 1, Knickerbocker Press: New York, USA, 1903.

[3] McMenamin, M.A.S. Deep Time Analysis, Springer: Cham, Switzerland, 2018.

[4] Szczygielski, T.; Drózdz, D.; Surmik, D.; Kapuscinska; Rothschild, B.M. New tomographic contribution to characterizing mesosaurid congenital scoliosis. PLOS ONE 2019, 14, e0212416.

[5] Benton, M.J.; Donoghue, P.C.J. Palaeontological evidence to date the tree of life. Molecular Biology and Evolution 2006, $24,26-53$.

[6] Bickelmann, C.; Müller, J.; Reisz, R. The enigmatic diapsid Acerosodontosaurus piveteaui (Reptilia: Neodiapsida) from the Upper Permian of Madagascar and the paraphyly of "younginiform" reptiles. Canadian Journal of Earth Sciences 2009, 46, 651-661.

[7] Reynoso, V.-H. An unusual aquatic sphenodontian (Reptilia: Diapsida) from the Tlayua Formation (Albian), central Mexico. Journal of Paleontology 2000, 74, 133-148.

[8] Leal, M.; Knox, A.K.; Losos, J.B. Lack of convergence in aquatic Anolis lizards. Evolution 2002, 56, 785-791.

[9] Piñeiro, G.; Ferigolo, J.; Ramos, A.; Laurin, M. Cranial morphology of the Early Permian mesosaurid Mesosaurus tenuidens and the evolution of the lower temporal fenestration reassessed. Comptes Rendus Palevol 2012, 11, 379-391.

[10] Shikama, T.; Ozaki, H. On a reptilian skeleton from the Palaeozoic formation of San Paulo, Brazil. Transactions and Proceedings of the Palaeontological Society of Japan, New Series 1966, 64, 351-358.

[11] Araújo, D.C. Taxonomia e Relações dos Proganosauria da Bacia do Paraná. Anais da Academia Brasileira de Ciências 1976, 48, 91-116.

[12] Carroll, R.L. Plesiosaur ancestors from the upper Permian of Madagascar. Philosophical Transactions of the Royal Society of London B 1981, 293, 315-383.

「137 Invce. W.G.: Parham. I.F.: Gauthier. I.A. Develoning a phylogenetically defined clade names, as exemplified by turtles. Journal of Paleontology 2004, 78, 989-1013.

[14] Currie, P.J. Hovasaurus boulei, an aquatic eosuchian from the upper Permian of Madagascar. Palaont. afr. 1981, 21, 99-168.

[15] Villamil, J.N.; Demarco, P.N.; Meneghel, M.; Blanco, R.E.; Jones, W.; Rinderknecht, A.S.; Laurin, M.; Piñeiro, G. Optimal swimming speed estimates in the Early Permian mesosaurid Mesosaurus tenuidens (Gervais 1867) from Uruguay. Historical Biology 2015, 28, 963-971.

[16] Haughton, S.H. On reptilian remains from the Karoo Beds of East Africa. Quarterly Journal of the Geological Society 1924, $80,1-11$.

[17] Currie, P.J. The osteology and relationships of Tangasaurus mennelli Haughton (Reptilia, Eosuchia). Annals of the South African Museum 1982, 86, 247-265.

[18] Simpson, G.G. A new fossil snake from the Notostylops Beds of Patagonia. Bulletin of the American Museum of Natural History 1933, 47, 1-22.

[19] Thomason, J.J., Ed. Functional Morphology in Vertebrate Paleontology, Cambridge University Press: Cambridge, Great Britain, 1998.

[20] Imagawa, I.; Shogaki, K.; Uehara, M. Interaction between glycogen body cell and neuron: examination in co-culture system. The Journal of Veterinary Medical Science 2006, 68, 1081-1087.

[21] Giffin, E.B. Gross spinal anatomy and limb use in living and fossil reptiles. Paleobiology 1990, 16, 448-458.

[22] Wescott, W.A..; Diggens, J.N. Depositional history and stratigraphical evolution of the Sakamena group (Middle Karoo Supergroup) in the southern Morondava Basin, Madagascar. Journal of African Earth Sciences 1998, 27, 461-479.

[23] Smith, R.M.H. Sedimentology and taphonomy of Late Permian vertebrate fossil localities in southwestern Madagascar. Palaeontologia africana 2000, 36, 25-41.

[24] Kusuma, A. The Organization of the Spinal Cord in Reptiles with Different Locomotor Patterns. Dissertation, Catholic University of Nijmegen, Netherlands, 1979.

[25] Donkelaar, H.J.; Kusuma, A.; de Boer-Van Huizen, R. Cells of origin of pathways descending to the spinal cord in some quadrupedal reptiles. The Journal of Comparative Neurology 1980, 192, 827-851.

[26] Jeong, J.; McMahon, A.P. Growth and pattern of the mammalian neural tube are governed by partially overlapping feedback activities of the hedgehog antagonists patched 1 and Hhip1. Development 2005, 132, 143-154.

[27] McMenamin, M.A.S. Dynamic Paleontology, Springer: Cham, Switzerland, 2016.

[28] Nagashima, H.; Sugahara, F.; Takechi, M.; Ericsson, R.; Kawashima-Ohya, Y.; Narita, Y.; Kuratani, S. Evolution of the turtle body plan by the folding and creation of new muscle connections. Science 2009, 325, 193-196.

[29] Christ, B.; Huang, R.; Scaal, M. Amniote somite derivatives. Dovolnnmontal Dunamirs $\mathbf{9 0 0 7}$ 36 728?_3206 
[30] Turner, M.L.; Sidor, C.A. Pathology in a Permian parareptile: congenital malformation of sacral vertebrae. Journal of Zoology 2018, 304, 13-20. 